\title{
Photoelectrochemical Properties of Nanostructured Copper Oxides Formed Sonoelectrochemically
}

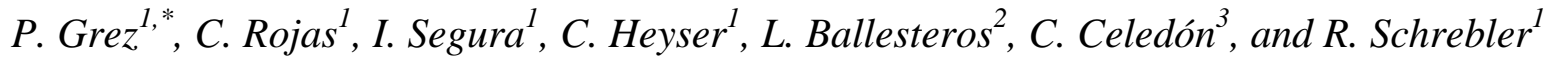 \\ ${ }^{1}$ Instituto de Química, Pontificia Universidad Católica de Valparaíso, Avda. Universidad 330, \\ Curauma, Placilla,Valparaíso Casilla, 4059 Valparaíso, Chile \\ ${ }^{2}$ Laboratorio de Síntesis Inorgánica y Electroquímica, Facultad de Ciencias, Universidad de Chile. Las \\ Palmeras\#3425, Ñuñoa, Santiago-Chile \\ ${ }^{3}$ Departamento de Física, Universidad Técnica Federico Santa María, P.O. Box 110-V, Valparaíso, \\ Chile \\ *E-mail: paula.grez@pucv.cl
}

doi: $10.20964 / 2017.08 .28$

Received: 24 March 2017 / Accepted: 28 May 2017 / Published: 12 July 2017

In this work nanostrutured copper oxides $\left(\mathrm{Cu}_{\mathrm{x}} \mathrm{O}\right)$ were prepared by ultrasound-assisted anodization of copper foils. These $\mathrm{Cu}_{\mathrm{x}} \mathrm{O}$ nanostructures were characterized morphologically and structurally by SEM and XRD, respectively. The bandgap value was determined by diffuse reflectance measurements. The electrochemical characterization included Mott Schottky plots and electrochemical techniques. From these measurements it was possible to establish that the formed phase corresponded to $\mathrm{p}-\mathrm{Cu}_{2} \mathrm{O}$. The best results in the cathodic photocurrent response for the system $\mathrm{Cu}\left|\mathrm{p}-\mathrm{Cu}_{2} \mathrm{O}\right| 10 \mathrm{mM} \mathrm{KI}, 1 \mathrm{mM} \mathrm{KI} \mathrm{I}_{3}$ in $50 \mathrm{mM} \mathrm{Na} 2 \mathrm{~B}_{4} \mathrm{O}_{7}(\mathrm{pH} 9.2)$ were obtained with oxides prepared at $75^{\circ} \mathrm{C}, 100 \mathrm{~V}$ in ethylene glycol contained $5 \%$ wt $\mathrm{H}_{2} \mathrm{O}$ and $0.5 \mathrm{wt} \% \mathrm{NH}_{4} \mathrm{Cl}$.

Keywords: nanostrutured copper oxides, sonoelectrochemical synthesis, photoelectrochemical properties

\section{$\underline{\text { FULL TEXT }}$}

(C) 2017 The Authors. Published by ESG (www.electrochemsci.org). This article is an open access article distributed under the terms and conditions of the Creative Commons Attribution license (http://creativecommons.org/licenses/by/4.0/). 